\title{
Unlocking the Archive
}

\author{
Jhava Chikli \\ Co-founder of ARTCHIVIUMlab \\ 13 bis rue de la Cour des Noues 75020 Paris \\ studio@artchiviumlab.com
}

\author{
Melanie Rozencwajg \\ Co-founder of ARTCHIVIUMlab \\ 40 Quai de Jemmapes, 75010 Paris \\ studio@artchiviumlab.com
}

\begin{abstract}
Today, archives are at the centre of a fascinating turning point in museography. This paper examines how archival materials were first brought within the sphere of exhibition design. It then explores the particularities of archival documents and considers the new perspective which the digital age has lent to their treatment, with the shift that has occurred in the past decade or so in the role of museums leading to the integration of interactive displays. With three practical examples, the paper looks at case studies carried out by ARTCHIVIUMlab, a media design studio working exclusively with archives, and reflects on the historically-based, but innovative approach that has been applied to each project in an effort to present archive material in a way which speaks to the contemporary public.
\end{abstract}

Archives, Exhibition Design, Media Design

\section{INTRODUCTION}

As direct witnesses to history, archival materials are displayed in museums and exhibition spaces for their historical value as well as for their aesthetic qualities. But the encounter with an archival document in a museum is not as simple or evident as it first appears. For the museum has taken the archival matter out of its original environment in the archive itself, where it played a purely administrative role, to transform it into an exhibition object. This move from depository to exhibition space constitutes a radical change first brought about with the reform of the secret state in revolutionary France, which provided free access to the public archives as a way of upholding and guaranteeing the principle of democracy under the new regime.

\section{ARCHIVES AND EXHIBITION DESIGN}

The next step in the process came in 1867, the same year as the Universal Exhibition, when a museum of Archives, dedicated to the history of France was opened at the Hotel de Soubise. The museum was the brainchild of Leon de Laborde, archaeologist, diplomat and, significantly, director of the Imperial Archives, and represented the first successful effort to take archival documents out of the archives themselves in order to present them directly to the public. Some eighteen hundred documents, carefully selected and displayed in a chronological order, were chosen to tell the history of France in an exhibition designed to promote national unity and to celebrate France's past.
Since that time archival materials have held a key place in museum exhibitions. Among the plethora of books dedicated to the history of exhibitions in the $20^{\text {th }}$ century, it is rare to be able to pinpoint any concise description of the development of archive exhibition. And particularly in the field of contemporary museography, one has the feeling that archives have a potential that has not yet been fully exploited.

The specificity of archives is that they combine both an aesthetic and a historical element. But they are also fragile, delicate, and can also appear recalcitrant to the uninformed viewer. Therefore their treatment requires a particular approach, which should take into account all of the aforementioned attributes.

Today, archives are at the centre of a fascinating turning point in exhibition design. Curators on the one hand have become aware of the fact that archival documents are fragile and have a limited lifespan. At the same time, museum designers have come to understand that today's general public will not interact with archival materials presented as mere visual 'objects'. The third element in the equation is the recent explosion of the digital age leading to the 'dematerialisation' of much of our historical legacy.

Over the past few years, new museums have been popping up at a rapid rate and their role and purpose has undergone a fundamental shift. They are seen less and less as mere repositories of objects and more and more as a venue for entertainment, engagement and education. 
Nowadays visitors seek a more interactive and engaging experience with museums, with the consequence that interactive displays play an increasingly important role. But the digital alone has repeatedly proven insufficient in itself to create a more engaging experience between the visitor and the content. There is a potential for the medium to overpower the content, confining the visitor's experience to the level of the technological. After the early excitement surrounding the technological discoveries, a more mature approach is now being sought whereby participants in the field of museum design are looking to use innovative technology in a more meaningful and profound way while continuing to observe the three principles of entertainment, engagement and education.

\section{ARTCHIVIUMLAB}

It is in response to that essential question: "How to exhibit archives in the digital age" that we decided to open ARTCHIVIUMlab, a media design studio working exclusively with archives. Operating at the crossover between art, design and technology, the studio dedicates its practice to giving archives new forms of visual expression and bringing them to life by infusing new into old.

We, the co-founders, believe that our respective backgrounds in history and visual design have imbued us with a certain sensitivity to the particularities of archival documents in their historical and visual context. We therefore decided to take archives as the 'source material' of our work and dedicate our research and practice exclusively to that material, with a particular focus on conceiving ways to 'unlock the archives' and render them more accessible to the contemporary public.

Each project brings up new issues, raises fresh questions and forces us constantly to apply innovative strategies to reveal the story behind the archive.

We should like to use this paper as an opportunity to share with you in a pragmatic way various challenges with which we were confronted while working on three particular projects.

\section{CASE STUDIES}

\subsection{Animation}

For the redesign of the Jewish Museum in Paris's permanent exhibition, ARTCHIVIUMlab was asked to create two films to be projected side by side using photographs of ethnographic expeditions dating from 1910 and taken in the provinces of the Russian Empire.

\subsubsection{Brief}

8 ethnographic photographs of Jewish towns in Russia (S. Anski Collection)

\subsubsection{Challenge}

To convey the living dimension inherent in the images

\subsubsection{Solution}

To create for the visitor an immersive and cyclical journey through the places photographed

\subsubsection{Result}

Installation of 2 films side by side: a double lateral camera travelling is created in a three-dimensional map created out of still images.

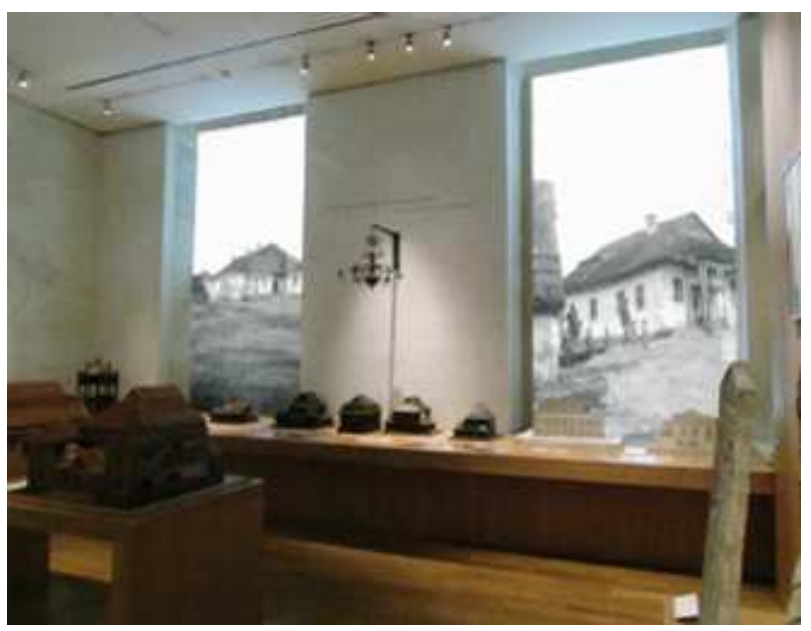

\section{2 Database}

ARTCHIVIUMlab was commissioned by a foundation to look at ways of presenting the personal archive collection of George X, through digital media. This project accompanies his soonto-be published biography.

\subsubsection{Brief}

300 family travel photographs and documents from George X private collection.

\subsubsection{Challenge}

To access a database in a stimulating and interactive way.

\subsubsection{Solution}

To transform the visitor into a traveller in the mold of George $X$ who was himself a keen traveler and to enable him to customize his journey.

\subsubsection{Result}

Multimedia platform: interactive family album with multiple navigation options (chronological, geographical, thematic).

\subsection{Interactive game}


For the exhibition of the Bruckenthal Collection taking place at the Villa Vauban in Luxembourg, ARTCHIVIUMlab has developed an interactive game dedicated to the painting The Massacre of the Innocents, which is currently housed in Sibiu, Romania. To unravel the mystery of its provenance and production, the IRPA, a laboratory specialising in works of art, conducted a thorough analysis and complete restoration of the painting,

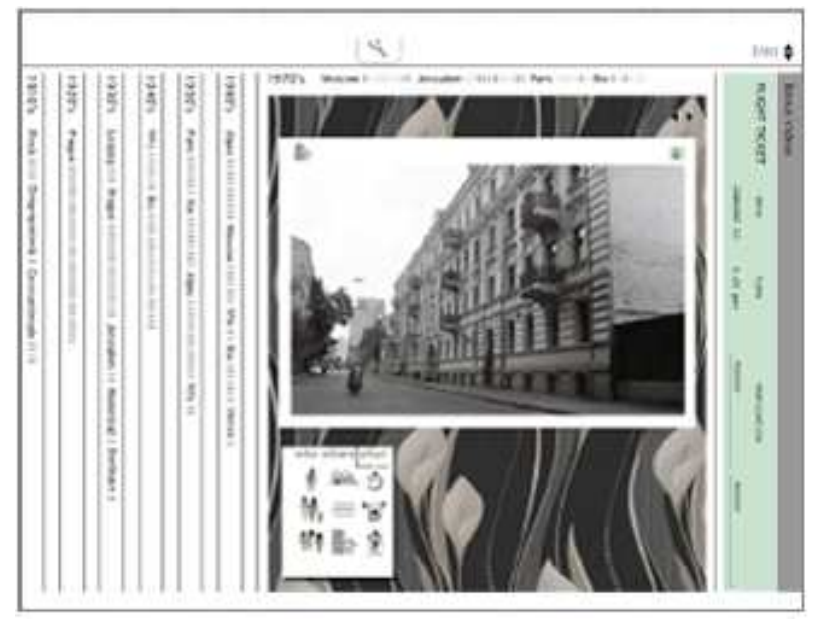

involving the making of numerous photographs, infrared scans and records. Their main task was to ascertain who painted the painting: Bruegel the Elder or Brueghel the Younger...

\subsubsection{Brief}

For this purpose, ARTCHIVIUMlab was asked to create a stimulating interactive application which would be at once educational and enjoyable, to allow the visitor to uncover the mystery behind the painting.

\subsubsection{Challenge}

To create a simple interface which would let the visitor explore the painting in its detail as well as in its depth (various layers) and obtain historical and pictorial information without inundating the painting with too many additional visual elements.

\subsubsection{Solution}

To integrate three levels of information into one interactive tool. The tool acts first as a magnifying glass, second as an index detector and third as a scanner to analyse the different layers/areas of the painting.

\subsubsection{Result}

An investigation game that approaches the painting The Massacre of the Innocents as a crime scene. Through the interactive interface and the sampling tools made available to him, the visitor inspects the painting in search of five clues embedded among 30. Each clue is transmitted to the laboratory which sends back to the player its own analysis helping him to solve the riddle: who is the author of the painting?

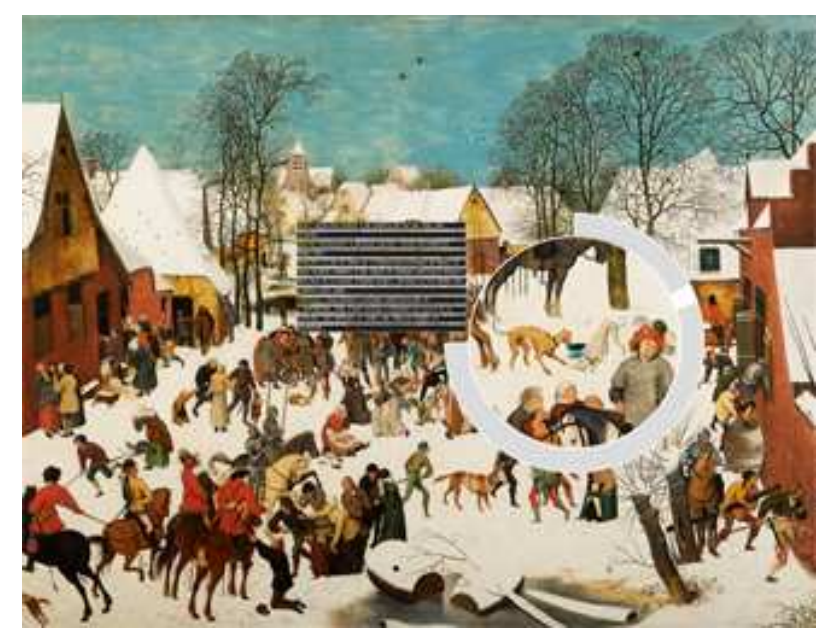

\section{REFERENCES}

Appundurai, A. (2003) Archive and Aspiration in Information is Alive, Rotterdam, V2_/NAi Publishers

Bietry-Rivierre, A. (2010) Nouveaux territoires scenographiques. Movement 54: 98-99,

Cassonn, D. (2002) Interactivity in Museum. Maazin FX.

Derrida, J. (1995) Mal d'archives. Ed. Eyrolles, Paris.

Foster, H. (2004) An Archival Impulse 110: 5.

Hughes, P. (2010) Exhibition Design. Ed. Eyrolles, Paris.

James-Sarazin (2009) Les archives s'exposent. Ed.

Association des archivistes français, coll. Les Petits guides des archives, Paris.

McLuhan, M. (1964) Understanding Media: The extensions of man.

Miller, A. (2006) From object to observer. Eye 61/06: 43-50. 